\title{
Peculiar Properties of Mathematics Teacher Training in Ukraine
}

\author{
N. Tarasenkova ${ }^{1}$, O. Chashechnikova ${ }^{2}$, I. Bogatyreva, ${ }^{1, *}$ \\ ${ }^{1}$ Department of Mathematics and Math training technique, National Bohdan Khmelnitsky University, Cherkassy, Ukraine \\ ${ }^{2}$ Contents and methods of teaching Mathematics, Physics and Computer science Laboratory, Sumy State Pedagogical University \\ named after A.S. Makarenko, Sumy, Ukraine \\ *Corresponding author: i_bogatyreva@ukr.net
}

Received September 26, 2013; Revised October 10, 2013; Accepted November 14, 2013

\begin{abstract}
The article addresses main questions of training future teachers of mathematics in Ukraine. The offered training model can be used in the classes for teaching methods of mathematics. This model provides theoretical and practical training of students with fully described stages of such classes. The correspondent system of methodological tasks for the formation of methodological competencies, enabling to use modern educational technology during educational activities was constructed. The article describes the problem of teaching students to use dialogue educational technology on mathematics lessons. It offers students a system of task with great examples how to prepare math class using such dialog technology.
\end{abstract}

Keywords: mathematics training technique, training of mathematics teacher, dialogue technology, educational dialogue

Cite This Article: N. Tarasenkova, O. Chashechnikova, and I. Bogatyreva, "Peculiar Properties of Mathematics Teacher Training in Ukraine.” American Journal of Educational Research 1, no. 11 (2013): 490-495. doi: 10.12691/education-1-11-6.

\section{Introduction}

Reform and modernization of education in Ukraine is happening lately, cause updating requirements applicable to the methodical preparation of mathematics teachers. In particular, it has been proved that [1]:

- a future teacher should be trained as a creative personality for performing his professional activity;

- methodological disciplines contents and structure should be built in accordance with the basic professional functions and common methodological problems of teachers of mathematics based on humanistic values and orientation;

- the process of professional and technological skills formation in the course of studying the methods of teaching Mathematics should be targeted in correspondence with the pedagogical conditions that lead to its realization.

- the process of involving future educationalists in methodological educational-cognitive and scientificresearch activity should be systematic and goaloriented;

- students critical attitude to the results of their previous work and development of constructive ideas should be performed as far as enhancement of their professional activity and their own self-improvement.

The main tasks were indentified in the project of National strategy of education development in Ukraine for the period from 2012 up to 2021[2]. Main tasks include restructuring of the educational process on the grounds of "Developmental Education”, aimed at early detection of children's potential (capabilities) and their full disclosure with age and psychological characteristics. Due to purpose tasks, significant changes in the process of students training have been introduced for quality assurance of higher education of training mathematics teachers.

\section{Theoretical Training of Mathematics Teacher in Ukraine}

Long-established system of methodical training of mathematics teachers has been established in Ukraine. Its main stages are:

- theoretical training of students which involves the study of mathematical disciplines and methodological cycles;

- practical training of students providing for the passage of teaching practice in secondary schools Ukraine.

Today special importance is the problem of the formation in students their methodological knowledge to apply modern educational technology, designed to realize personal approach to learning during their pedagogical work. There are four groups of learning technologies, depending on the position of students in the educational process: information, adaptive, educational and individually oriented technologies.

Theoretical training od students in the disciplines of methodological cycle is carried out on the basis of 
educational and professional program "Article training of mathematics teacher”. Such program consists of courses aimed at opening the flow patterns of cognitive interest in the mathematical sense, the study of the theoretical aspects of the training content, organization and principles of operation of mathematical education. The program is built in a modular fashion. It highlighted the following modules: "Theoretical Foundations of general methods of teaching mathematics", "Methods of teaching of individual sections of the school course of mathematics primary school", "Methods of teaching of individual sections of the school course of mathematics high school", "Methods of teaching advanced mathematics course", "Formation mathematics teachers in the ability to solve multifaceted professional educational problems".

Study of relevant content modules provides for student the basis for the successful formation of teaching competencies of teachers of mathematics.

The teacher of mathematics should not only have a thorough knowledge of the subject, but also be prepared to quickly navigate the changes taking place in the modern school, to be able to continuously improve. Article training should be directed to the formation of students' skills quickly identify problems that arise in the course of teaching mathematics students, analyze them, identify the causes, seek out different ways of solving a problem situation, to evaluate the feasibility of using each of them under a particular situation. It also should summarize lessons learned use it in the future, improve, adapt to the changed or new conditions, critically evaluate and promptly abandon its use in the case of non-compliance with a particular situation.

In the process of studying a special course, orientation on the formation of the following features is realized [3].

- Ability to navigate the available information. This includes: knowledge of standards of school mathematics education, new programs in mathematics for schools and classes of various types; existing textbooks, presenting a critical analysis of specific topics in various textbooks, knowledge of material features of each of them. It also includes introduction to the system of mathematics teachers who work creatively and to new research methods in mathematics (through study the pedagogical press, attending lessons teachers who use innovative approaches and their subsequent analysis). The last feature is mastering various methods of theorem proving, solving problems and identifying matching their learning to material of School of Mathematics, age and individual needs of students of a particular class (specific group).

- Ability to work in schools of various types (including rural), in various fields. It includes knowledge of pedagogical and psychological methods of diagnosis. As well as knowledge of specific work with students, different orientation of interests and abilities. Inspection of the possibilities of interdisciplinary connections in the study of a topic, increasing the applied mathematics orientation (through the application of mathematical methods to the modeling and analysis of real situations, solving problems of applied nature under the chosen specialization, including - from unnecessary, excessive and insufficient data with approximate data with conflicting information) is also a feature. It includes also knowledge of the requirements for the major learning outcomes of students enrolled in classes in various fields.

- Ability to exercise individual approach to students. Knowledge of age and individual characteristics of students (especially attention, memory, temperament, etc.), features of work with different groups of students (gifted and talented children, slow-working students, students with special needs - impaired vision, hearing, etc.).

- Creative abilities in the pedagogical process. This feature includes compiling original author programs on a specific topic, appropriate selection and creation of exercises, selection, improvement of existing and creation of new visual learning tools and to develop effective methods of their use. It also includes development structure, content and methods of extracurricular activities, courses, extracurricular activities. The ability to quickly, flexibly, critically respond to changes in the program efficiently select and structure the learning material by theme, goals, and objectives of a particular lesson features a class of students. Ability to dialogic communication.

It is impossible to foresee all the changes that take place in the future in a system of mathematical schooling and education in general. Therefore, at this stage, the immediate problem is the formation of mathematics teachers willingness and ability to self-improvement and self-education, the capacity for rational organization of their own activities, familiarity with the basic principles of scientific organization of productive work, with elements of anger.

One of the qualities of creative teachers is openness to implement in his own practice of the results of new research, new techniques, thus, his willingness for implementation of new techniques in his own work and his research activity should be formed as a new mathematics teacher. Creative teacher is not only an executor that makes practical use of the ideas, but also is a competent member of the development process issues. If the teacher is not even an independent researcher in the full sense of the term, but he must be able to objectively assess the appropriateness or unreasonableness of the proposed methodological innovation in the practice of his own work on the basis of objective, thorough analysis, comparing them with existing methodologies and technology training [3].

Particular attention is paid to the formation of teaching competencies that provide with the opportunity of applying modern educational technologies in teaching activity. In our opinion, one such technology is interactive technology that is based on the use of educational dialogue.

Dialogic technology is the method of mathematics studying process through educational dialogue [4]. Depending on an educational problem we highlight the following types of educational dialogue: training and supervising.

\subsection{The System of Teaching Tasks to Prepare Math Lesson}

We use a specially designed system of methodological problems for methodic training of students concerning the 
construction and maintenance of educational dialogue at various stages of studying mathematics. Here are some examples of tasks that facilitate the formation of appropriate skills to use educational including cognitivetheoretical dialogue in educational activities.

Cognitive-theoretical dialogue is a kind of educational dialogue that is conducted at the stage of studying new material, and is problematic in character. The main purpose of this dialogue is to develop students to stimulate their cognitive interest, engaging students in active discussion, the impulse to self-solve problem situations that arise. In the process of constructing cognitivetheoretical dialogue teacher with the help of problematic issues and cognitive tasks creates problematic situations that push students to self-search activities.

We offer students the following rules for constructing cognitive-theoretical dialogue:

- the system of questions must be constructed in the logical sequence, i.e. each succeeding question is logical continuation of the answer to the previous one;

- questions should carry problematic load, but still be feasible for students;

- learners' answers to the questions should be full and reasoned;

- if a learner does not know the answers to the questions, an additional question that leads him to answering should be asked;

- quite important to listen the answer of the student without interrupting him by making remarks or asking him additional questions.

Based on the fact that the training dialogue is a complex form of the educational process, we distinguish two stages in the preparation of students. At the first stage, students solve the methodological problem that are preparatory in character, and the second they solve methodological problems that are more general in character. For example, in the study of methods of forming mathematical concepts we offer students the following system tasks.

Task 1. Construct a system of questions to a certain stage of formation of the given mathematical notion.

Task 2. Analyze the suggested lesson fragment of mathematical notions introduction using cognitivetheoretical dialogue.

Task 3. Find methodological errors in the cognitivetheoretical dialogue for the proposed lesson fragment of mathematical notions introduction.

Task 4. Develop in groups a lesson fragment of the given mathematical notion introduction using cognitivetheoretical dialogue.

Task 5. Develop independently a lesson fragment of the given mathematical notion introduction using cognitivetheoretical dialogue.

As an example for completing task 5, consider the fragment of the geometry lesson in the 7th form on the topic: "Exterior angle of a triangle", in which it is reasonable to apply cognitive-theoretical dialogue while studying the properties of the exterior angle of the triangle.

Before we formulate and prove the theorem, we suggest to the learners completing the following practical task that makes for problematic situation creation.

Practical task. On the segment $A B, 4 \mathrm{~cm}$ long, construct a triangle $A B C$ with angles $A$ and $B$, respectively equal to $50^{\circ}$ and $60^{\circ}$.

1. Determine the degree measure of angle $C$.
Expected answer:

$$
\angle C=180^{\circ}-(\angle A+\angle B)=180^{\circ}-\left(50^{\circ}+60^{\circ}\right)=70^{\circ} \text {. }
$$

2. Construct the exterior angle $B C D$ at the vertex $C$.

3. Determine the degree measure of the angle of $B C D$. Expected answer:

$\angle B C D=180^{\circ}-\angle C=180^{\circ}-70^{\circ}=110^{\circ}$.

4. Find the sum of the angles $A$ and $B$ of the triangle $A B C$.

Expected answer: $\angle A+\angle B=50^{\circ}+60^{\circ}=110^{\circ}$.

5. Compare the degree measure of the angle $B C D$ and the sum of angles of the triangle $A$ and $B$.

Expected answer: degree measures of $B C D$ angle and the sum of the angles of $A$ and $B$ triangle are equal.

6 . Formulate a hypothesis about the property of the triangle exterior angle. Test your hypothesis by the book [[4], p. 84].

Thereafter, using the constructed triangle $A B C$ one can formulate and prove a theorem on the property of the exterior angle of the triangle. The proof may include the following system of questions.

1 . What is the sum of the angles of this triangle?

Expected answer: $\angle A+\angle B+\angle C=180^{\circ}$.

2. From the obtained equation, express the amount $\angle A$ $+\angle B$.

Expected answer: $\angle A+\angle B=180^{\circ}-\angle C$.

3 . Determine the degree measure of the exterior angle $B C D$ at the vertex $C$.

Expected answer: $\angle B C D=180^{\circ}-\angle C$.

4. Compare the degree measures of the values $\angle A+\angle B$ и $\angle B C D$.

Expected answer: $\angle B C D=\angle A+\angle B$.

After proving the theorem it is reasonable to suggest to the learners answering the following questions.

1. Which angles of the triangle can be found if the exterior angle of the triangle is known?

2. Is it possible to find the angles of a triangle, knowing the degree measure of the exterior angle of a triangle? Justify your answer.

Add the tasks on creativity.

Task 6. Analyze the given educational topic and prepare the lessons applying cognitive-theoretical dialogue.

Students conduct analysis of an educational topic according to the plan: 1) to analyze theoretical material and choose the parts in it that can be presented with the help of a dialogue, 2) to formulate the purpose of learning a new material, 3) to draw the conclusions that the teacher should lead students to, during the dialogue; 4) to select the question (or the task) with which a dialogue begins; 5) to prepare questions and tasks for dialogue conduction, as well as think over the expected answers and the ways of solving the tasks, 6) to prepare the system of prompting questions and leading tasks in case of difficulties emergence among the students; 7) to consider alternative ways of dialogue conduction on the subject.

Task 7. Analyze a particular educational topic and prepare lesson fragments for classes of different types.

Task 8 . Think over the system of questions, aimed at students' creative activity organization while solving the task: "Study whether a quadrangle that has equal diagonals and the diagonals intersect at the right angle is always a rhomb?" 
Task 9. Prepare a system of tasks, in which a few requirements can be put to one condition. One of the solution examples: "Equilateral triangle $A B C$ is given. The altitudes $A A_{1}$ and $C C_{1}$ are drawn, they intersect at $P$. Prove: 1) equality of triangles $A A_{1} C$ and $\left.C C_{1} A ; 2\right)$ triangle $A P C$ is isosceles; 3 ) equality of triangles $A P C_{1}$ and $C P A_{1}$ ".

It should be stated that the proposed system of methodological problems contributes to forming in students the corresponding basic professional skills, as well as creative approach to organizing and conducting mathematics lessons.

\subsection{The System of Methodological Problems for Special Training how to Solve Tasks}

Another kind of educational dialogue is the dialogue conducted on the stage of solving the tasks, and we define it as cognitive-practical dialogue. Such kind of dialogue allows a teacher, by applying specially selected leading questions (prompting questions), to urge the learners on to the idea of solving the problem or leads them to independent, and what is more important, to conscious solving of a new or complicated for them task [6].

We suggest the following system of methodological problems for teaching to students the rules of cognitivepractical dialogue organization and conduction.

Task 10. Make up a system of questions to the particular stage of solving the problem.

Task 11. Analyze cognitive-practical dialogue system of questions for the proposed solution of the problem.

Task 12. Find methodological errors in cognitivepractical dialogue for the proposed solution of the problem.

Task 13. Develop in groups a solution using cognitivepractical dialogue.

Task 14. Develop independently a solution using cognitive-practical dialogue.

As an example of completing the latter tasks, the following cognitive-practical dialogue, used in solving the problems of the advanced level that is marked in the textbook [5] with an asterisk, can be suggested.

Task $46 *$ [[5], p. 89]. In the triangle $A B C$ from the vertex $B$, altitude and bisector are drawn. Find the angle between the altitude and the bisector if $\angle A=40^{\circ}$ и $\angle B=$ $60^{\circ}$.

The plan of solving this problem suggests applying of the following educational dialogue.

1. Identify the type of triangle $A B K$, if $B K$ is the altitude.

Expected answer: triangle $A B K$ - rectangular and angle $A K B$ is equal to $90^{\circ}$.

2. Determine the degree measure of the angle $A B K$.

Expected answer: $\angle A B K=90^{\circ}-40^{\circ}=50^{\circ}$.

3. What can be defined if $B M$ is the bisector of angle $B$ ?

Expected answer: since $B M$ is the bisector of angle $B$, then $\angle A B M=\angle M B C=60^{\circ}: 2=30^{\circ}$.

4. How can the degree measure of the angle $M B K$ be defined?

Expected answer:

$\angle M B K=\angle A B K-\angle A B M=50^{\circ}-30^{\circ}=20^{\circ}$.

It should be noted that the system of questions (the sequence of questions, their completeness and complexity) during cognitive-practical dialogue conduction depends on the level of academic grounding of the class as a whole or on the level of academic grounding of each individual learner, to whom the present question is addressed.

\section{Practical Training of Mathematics Teacher}

\subsection{Educational Modeling Professional Mathematics Teacher}

Methodological training of students should be carried out in 2 directions: in the process of educational cognition while studying theoretical and professionally oriented disciplines and in the conditions of educational modeling of future professional activity. The following models of teaching process organization, conditioned by the specific character of training for the future profession are distinguished: semiotic, imitation, social models [1]. Consider the peculiarities of imitation training model realization.

Imitation model of the educational process organization stands for complex inclusion in the process of educational activity a system of tasks aimed at modeling the situations of the future professional activity that requires from students analysis conducting and decision making on the basis of the suggested by the teacher specific information [7].

Professional activities of students as future mathematics teachers form the basis of this model realization. The main purpose is to create conditions for entering the profession of mathematics teacher by means of "living out" different situations in class that get imitated in the process of training. For example, while studying methodology mathematical notions formation, we suggest to students the following system of tasks.

Task 15. Conduct a fragment of lesson-imitation of the given mathematical notion introduction using cognitivetheoretical dialogue.

These lessons-imitations should be conducted prior to conducting students' teaching practice in laboratory classes in the form of a role-playing game. In the process of this role-playing game the personality of the future mathematics teacher gets revealed, his capabilities get manifested, personalized prospects for the future educational activity get disclosed.

Characteristic features of the role-playing game are [[7], p. 30]: 1) presence of psychological and educational situation; 2) roles allocation; 3) interaction of the game participants while playing; 4) presence of the common purpose in the playing group; 5) interpersonal skills, tact of the participants, mutual support; 6) diversity in decision making; 7) presence of group or individual assessment of the game participants' play.

It should be noted that significant preparatory work precedes conducting role-playing games in the form of lessons-imitations. Students of the University complete the following educational tasks:

- visit and discuss lessons of experienced mathematics teachers at schools of our town;

- write and discuss in groups lesson-plans on the given topic;

- brainstorm different situations in the classroom;

- perform theoretical modeling of student's activity with a certain level of development and academic performance, including foreseeing possible difficulties while perceiving a new learning material, the errors and inconsistencies in application of new 
knowledge and skills on the part of the students in the process of solving the problems.

After completing these tasks, students' readiness for independent lessons conduction, beginning from lessonsimitations conduction, and then - lessons conduction during their teaching practice is formed.

\subsection{Example of Professional Mathematics Teacher Activity Modeling}

Here is a fragment of the role-playing game "Geometry lesson in the 7th form." Allocation of roles ("teacher", "learner", "methodist", etc.) for the lesson-imitation can be different: on students' request or on teacher's recommendation. However, it should be noted that the role of a "weak student" as opposed to the role of an "excellent student" is the most difficult one, because student's behavior and academic grounding, that the student has to model are conditioned by various factors.

In the process of preparing for the lesson, a student"teacher" can be proposed to complete the following task.

Task. You need to conduct Geometry lesson in the 7th form on the topic: "Properties of triangle angles. Exterior angle of a triangle". It is the second lesson on this topic.

There are 32 schoolchildren in class. They are: learners with high academic achievements in the present subject -8 , with sufficient academic achievements -12 , with average academic achievements - 10, with low academic achievements - 2. Obvious discipline violators 4.

Geometry lesson is the first lesson scheduled on this day.

Note that while preparing for the lesson-imitation and writing a lesson-plan, a student-“teacher" should not just think over the course of the lesson, but also foresee possible variants of students' answers according to the level of their academic achievements in compliance with the conditions of the suggested task. Before the lesson conduction, the students of the group allocate their roles of "learners" according to the set tasks.

An important factor for class conduction is didactically weighed management over the lesson-imitation course. In case of necessity, a teacher should interfere in the course of the lesson by means of certain modeled situation, about which the student-"teacher" is not warned beforehand. Teacher should consider such situations and formulate additional tasks on their basis in advance. For example, in the process of completing the task that is being considered, the following additional tasks can be suggested:

1. A pupil is late 5 minutes for your class. What will be your reaction?

2. After introducing the term: "exterior angle of a triangle" a pupil makes a mistake in its definition. What will be your reaction?

Will your actions be different and in what way, depending on the fact which pupil (who has a certain level of academic achievements) has made a mistake?

3. Before solving the problems, the learner with a sufficient level of academic achievements states that he hasn't understood how many exterior angles a triangle has. What will be your reaction?

4. A learner with high academic achievements while solving the problem at the blackboard has made a mistake. What will be your reaction?
Consider the following methodological tasks that we suggest to students after conducting the lesson-imitation.

Task 16. Analyze the observed lesson-imitation fragment of the given mathematical notion introduction by applying cognitive-theoretical dialogue.

Task 17. Analyze the observed lessons conducted by mathematics teachers, who use interactive technology in the educational process. Propose your own fragment of conduction of one of the observed lessons.

Task 18. Choose the topic independently and work out a lesson using cognitive-theoretical dialogue.

Task 19. Analyze the given educational topic and prepare the lessons that are reasonable to conduct using cognitive-theoretical dialogue.

For completing the latter tasks we suggest to students the following scheme of preparation a cognitivetheoretical dialogue that is used in mathematics classes:

1. analyze theoretical material and select the parts that are reasonable to be presented with the help of educational dialogue;

2. specify the purpose of learning a new material;

3. draw the conclusions to which students should be lead in the course of the dialogue.

4. select the question (or the problem), from which educational dialogue will begin;

5. prepare the questions and tasks for educational dialogue conduction and think over learners' expected answers and solutions;

6. prepare a system of prompting questions and leading tasks in case of difficulties' emergence among the learners;

7. consider alternative ways of dialogue conduction on the given topic.

It should be noted that we also use the present system of methodological tasks while working with methodology of studying the theorems.

\subsection{Pedagogical activity reflection of students}

For ensuring the quality of training mathematics teachers, the final stage should be conduction of one's reflection activity. With the purpose of providing introspection of pedagogical activity in the course of lesson-imitation conduction on the part of the student, we suggest the following tasks:

Task 20. Perform introspection of the conducted lessonimitation.

Task 21. Identify the errors in the course of educational dialogue during lesson-imitation conduction.

Task 22. Outline the ways of the conducted lesson improvement.

Referring to the work [8] and our own elaborations, we have identified the major errors in the course of educational dialogue conduction:

1) a monologue, eliminating the possibility of pupils' active participation in the educational process, had been suggested instead of the dialogue conduction;

2) student- "teacher" does not listen to learner's response to the end (both - the right one and the wrong one);

3) correction of students' mistakes is performed by the student-"teacher", instead of giving a counterexample or involving other learners in detecting and correcting the errors; 
4) student-“teacher” repeats after the pupil the dubbed text.

We believe that didactic examination of methodological errors, made by student-"teacher" is critical. That is why the lesson is divided into two parts: lesson-imitation is carried out in the first part of the class, and the second part we devote to the full and comprehensive analysis of the lesson. While analyzing the lesson, we pay special attention to the formation of personal attitudes of students to the things they observe. Consequently, in addition to application of the well-known scheme of the lesson analysis, each student defines the following: "If I pursued this lesson, I would change ...... during the lesson”.

Recently, we have practiced conduction of lessonimitation by several students; each of them conducts his own stage of the lesson. It allows involving more students in lesson conduction.

Working experience proves the fact that such roleplaying games ("rehearsals" of the teaching activity, in which students will be engaged during their teaching practice), provide students with the opportunity to not only "live out" the situation of the educational process in class, but also help them to better understand the psychology of its participants. During lessons-imitations conduction, students gain behaving experience in the conditions of pedagogical activity realization that requires immediate responses to emerging in class educational situations.

\section{Conclusions}

This article highlights 2 main areas of mathematics teacher training in Ukraine: mathematical training of students and preparation for the methodical work.

Mathematical training of students involves acquiring by the student mathematical knowledge and skills necessary for their future careers. The main components of it include: the content of courses (basic mathematical concepts, their properties and methods of solving math tasks); knowledge of the ways of knowing and describing the world by means of mathematics; ability to demonstrate the role of mathematics in the future careers of students.

Methodical preparation of students involves the formation of professional competencies required for the organization and conduct of the training process. Main constituents of methodical preparation include: ability associated with the analysis, systematization and generalization of experience in teaching mathematics in the educational institutions of II-III stage in Ukraine; knowledge of methodical methods and learning tools for training according to specific content, learning stage and knowledge level of participants; knowledge of the various systems and technologies of teaching mathematics and the ability to use them in the learning process.

Based on the nowadays requirements, the focus of methodological training of teachers must be put on the solution of methodological problems associated with the modeling of the teacher activities.

\section{Acknowledgement}

We would like to express gratitude to all the authors of the references who have helped us indirectly with their immortal books, journals while we were preparing this manuscript.

\section{Statement of Competing Interests}

The authors have no competing interests.

\section{References}

[1] Kuzminskiy, A.I., Tarasenkova, N.A., Akulenko, I.A, Scientific basis of future mathematics teacher methodological training, Publishing house of Bogdan Khmelnitsky National University at Cherkasy, Cherkasy, 2009, 320.

[2] National Strategy for Development of Education in Ukraine for the period of 2012-2021: the draft. [Online]. Available: http://www.president.gov.ua/documents/15828.html.

[3] Chashechnykova, O.S, Creating of a creative environment under condition of differential training of mathematics, Publishing house of PP Vinnychenko M.D., FOP Lytovchenko Ye.B, Sumy, 2011, 412.

[4] Bogatyreva, I.N, "Teaching of Mathematics by means of educational dialogue”, Bulletin of the University at Cherkassy, № 201, 11-15, 2011.

[5] Burda, M.I., Tarasenkova, N.A, Geometry 7, «Zodyak-Eko», Kyiv, 2007, 208.

[6] Chashechnykova, O.S, "Application of the system of prompts with the purpose of learners' mathematical capabilities development”, Mathematics at school, № 1, 44, 1998.

[7] Tarasenkova, N.A., Bogatyreva, I.M, "Imitation model of students-mathematicians teaching in the framework of their professional training”, Ridna Shkola, № 10, 42-44, 2011.

[8] Shcherban, P.M, Training and educational games at higher educational establishments, Vyscha shkola, Kyiv, 2004, 207.

[9] Malova, I.E, Continuous methodological preparation of mathematics teachers for realization of individually oriented pupils training, Publishing House of Bryansk State University, Bryansk, 2003, 225. 